\title{
Cancer-associated fibroblast regulation of tumor neo-angiogenesis as a therapeutic target in cancer (Review)
}

\author{
FANG-TAO WANG $^{1 *}$, WEI SUN ${ }^{2 *}$, JING-TAO ZHANG $^{1}$ and YUE-ZU FAN ${ }^{1}$ \\ ${ }^{1}$ Department of Surgery, Tongji Hospital, Tongji University School of Medicine, Shanghai 200065; \\ ${ }^{2}$ Department of Surgery, Shanghai Tenth People's Hospital, Tongji University \\ School of Medicine, Shanghai 200072, P.R. China
}

Received June 12, 2018; Accepted December 21, 2018

DOI: $10.3892 / \mathrm{ol} .2019 .9973$

\begin{abstract}
Adequate blood supply is essential for tumor survival, growth and metastasis. The tumor microenvironment (TME) is dynamic and complex, comprising cancer cells, cancer-associated stromal cells and their extracellular products. The TME serves an important role in tumor progression. Cancer-associated fibroblasts (CAFs) are the principal component of stromal cells within the TME, and contribute
\end{abstract}

Correspondence to: Professor Yue-Zu Fan, Department of Surgery, Tongji Hospital, Tongji University School of Medicine, 389 Xincun Road, Shanghai 200065, P.R. China

E-mail: fanyuezu@hotmail.com

${ }^{*}$ Contributed equally

Abbreviations: CAF, cancer-associated fibroblast; TME, tumor microenvironment; VM, vasculogenic mimicry; ECM, extracellular matrix; VEGF, vascular endothelial growth factor; VEGFR, vascular endothelial growth factor receptor; PI3K, phosphoinositide 3-kinase; MMP, matrix metalloproteinase; Ln-5 2 , laminin 5 2 ; EphA2, ephrin type A receptor 2; FAK, focal adhesion kinase; $\alpha$-SMA, $\alpha$-smooth muscle actin; FAP, fibroblast activation protein; SDF-1, stromal cell-derived factor-1; HUVEC, human umbilical vein endothelial cell; MT1-MMP, membrane type 1-MMP; ROS, reactive oxygen species; EMT, epithelial-mesenchymal transition; GPER, G-protein-coupled estrogen receptor; HIF-1 $\alpha$, hypoxia-inducible factor-1 $\alpha$; EC, endothelial cell; AGM, angiomodulin; EPCs, endothelial progenitor cells; CXCR-4, CXC chemokine receptor type 4 ; TGF- $\beta$, transforming growth factor- $\beta$; COX-2, cyclo-oxygenase- 2 ; TGF- $\beta R$, TGF- $\beta$ receptor; VE-cad, vascular endothelial cadherin; HGF, hepatocyte growth factor; PDGF, platelet-derived growth factor; PDGFR, platelet-derived growth factor receptor; FGF, fibroblast growth factor; AM, adrenomedullin; CLIC3, chloride intracellular channel protein 3; PGs, prostaglandins; CLL, chronic lymphoid leukemia; FGFR, FGF receptor; eng, endoglin; VNR, vinorelbine

Key words: neoplasm, cancer-associated fibroblasts, tumor microenvironment, neo-angiogenesis, signaling pathway, target therapy to tumor neo-angiogenesis by altering the proteome and degradome. The present paper reviews previous studies of the molecular signaling pathways by which CAFs promote tumor neo-angiogenesis and highlights therapeutic response targets. Also discussed are potential strategies for antitumor neo-angiogenesis to improve tumor treatment efficacy.

\section{Contents}

1. Introduction

2. Blood supply for tumors

3. Tumor microenvironment and CAFs

4. Molecular signaling pathways by which CAFs promote tumor neo-angiogenesis

5. Potential therapeutic targets

6. Conclusions

\section{Introduction}

Metastatic growth relies on the microcirculation to provide adequate nutrients; as such, tumors require extra vascular formation by way of angiogenesis and vascular mimicry (VM) (1-4). Highly aggressive cancers are dependent on angiogenesis and/or $\mathrm{VM}$, making them potential targets for future therapies (5-7). However, to date, anti-angiogenic or anti-VM therapies have elicited only modest effects, suggesting that this approach alone may be ineffective $(8,9)$.

It has been suggested that the tumor microenvironment (TME), which contains various stromal cells as well as the extracellular matrix (ECM), is critical to tumorigenesis, tumor neo-angiogenesis and cancer progression $(10,11)$. Cancer-associated fibroblasts (CAFs), which are the primary stromal cells within the TME, may contribute to tumor neo-angiogenesis via proteomic and degradomic alterations $(12,13)$. As such, understanding how CAFs and tumor neo-angiogenesis interact may be beneficial for developing novel tumor treatments. In the present review, blood supply, TME, CAFs and other research focused on CAF regulation of tumor neo-angiogenesis are discussed. Also reviewed are the underlying molecular signaling pathways and potential anti-angiogenic and anti-VM therapeutic targets. 


\section{Blood supply for tumors}

Tumor angiogenesis is essential for providing adequate nutrition for tumorigenesis and tumor progression; without angiogenesis, tumors are unable to grow and metastasize. Angiogenesis is associated with the ECM, which provides structural support and delivers molecular signals during all stages of tumor angiogenesis $(5,6,11)$. Drugs that are able to block angiogenesis-dependent tumor growth are of great interest, particularly the use of cleaved proteins, monoclonal antibodies, synthetic small molecules and natural products. A number of angiogenic inhibitors, including bevacizumab [a vascular endothelial growth factor (VEGF) inhibitor], sorafenib, sunitinib [a VEGF receptor (VEGFR) and platelet-derived growth factor receptor (PDGFR) inhibitor], erlotinib (an epidermal growth factor receptor inhibitor), thrombospondin-1 [a VEGF and fibroblast growth factor (FGF) inhibitor], TNP-470 [a methionine aminopeptidase-2 inhibitor], SU-5416, endostatin (a VEGFR inhibitor), celastrol and angiostatin, have been reported to have antitumor and anti-angiogenic activities $(6,14-17)$. However, previous studies suggest that anti-angiogenic therapy has limited benefits and that blocking angiogenesis alone may not be effective $(8,9)$. As such, combination treatments may provide improved anti-angiogenic and antitumor activities $(6,18,19)$.

VM, a newly defined pattern for tumor blood supply, differs from angiogenesis and vasculogenesis as it does not require endothelial cells (ECs), allowing highly aggressive tumor cell behavior and the expression of EC-associated genes to form ECM-rich tubular networks (4). This provides the required microcirculation for tumor growth and is associated with poor prognosis in patients with highly aggressive malignant tumors, such as melanoma and gallbladder cancer (3,7,20-22). The molecular mechanisms underlying tumor VM formation are associated with activation of the phosphoinositide 3-kinase $(\mathrm{PI} 3 \mathrm{~K}) /$ matrix metalloproteinases (MMPs)/laminin $5 \gamma 2$ (Ln-5 2 2), epithelial cell kinase/ephrin type A receptor 2 (EphA2)/focal adhesion kinase (FAK) and VEGF- $\alpha$ signaling pathways (7). VM formation in human gallbladder was identified to be triggered by activation of the PI3K/MMPs/Ln-5 22 and EphA2/FAK/paxillin signaling pathways in three-dimensional matrices of GBC-SD cells in vitro and GBC-SD nude mouse xenografts in vivo (23-26). Anti-angiogenic therapy has been identified to exhibit promising effects on VM in pancreatic cancer, hepatocellular cancer, hepatoblastoma, breast cancer, glioblastoma, gastric cancer and ovarian cancer (27-34). However, owing to individual differences, these studies have not been applied clinically or, if they have, have had little effect. Considering the number of cells involved in angiogenesis and VM, as well as the different molecular regulation mechanisms, further understanding of the underlying molecular mechanisms of tumor microcirculation is required in order to investigate joint targets and develop novel drugs that target angiogenesis and VM.

\section{Tumor microenvironment and CAFs}

The majority of human tumors originate from cancer epithelial cells, and for years tumors were considered to be transformed cells with cell-autonomous hyperproliferative and invasive properties. On this basis, treatments were targeted at the tumor itself. However, with the emergence of drug resistance and anti-angiogenic tolerance, tumor occurrence and development are associated with not only the tumor itself, but also with adjacent activated stromal cells and the associated chemokine and cytokine production $(10,11)$. Studies have indicated that tumor progression is associated with the microenvironment of the tumor-host interface, which comprises tumor and stromal cells, as well as genetic mutations and the unlimited proliferation of tumor cells. Cancer-associated stromal cells, including inflammatory cells, vascular cells and CAFs, have a complex tumor-stromal interaction $(10,11)$.

CAFs, which include activated fibroblasts or myofibroblasts around tumor epithelial cells, are the most important host stromal cells in the TME and regulate the microenvironment balance at the tumor-host interface via cell-to-cell contact, soluble factor secretion, ECM modification and promotion of malignant transformation of epithelial cells $(10,12,13)$. Unlike normal fibroblasts, CAFs express $\alpha$-smooth muscle actin ( $\alpha$-SMA), fibroblast activation protein (FAP) and fibroblast-specific protein-1; they have different gene expression profiles compared with normal fibroblasts $(10,12,13,35)$. CAFs mediate paracrine or autocrine factors between tumor and stromal cells to influence TME and affect tumor dormancy or growth, invasion, angiogenesis and therapeutic resistance $(10,12,13,35-39)$, all of which are associated with poor prognosis in patients with cancer $(40,41)$. Madar et al (42) proposed a novel description of CAFs to illustrate that they are not a single cell type, rather comprising various activated cells. Research indicates that CAF inhibition prolongs the survival of patients with pancreatic cancer compared with chemotherapy alone, and that anti-CAFs prevent tumor progression prior to tumor invasion (43-45).

CAFs have a stable genome, are not prone to antigen loss, are tolerant of chemotherapy, are heterogeneous and account for between 50 and $90 \%$ of solid tumors, as stromal cells are rich targets and have complex interactions with tumor cells. Therefore, CAFs and their markers may be effective targets of antitumor therapy and drug design $(42,43)$. However, crosstalk and interactions between CAFs and tumor cells and the underlying molecular mechanisms are not fully understood. It has been identified that stromal cell-derived factor-1 (SDF-1)/CXC chemokine 12 (CXC12) promotes angiogenesis in breast cancer (35) and VEGF secreted by CAFs promotes tumor angiogenesis (46). The use of conditioned media and human umbilical vein endothelial cells (HUVECs) in co-culture has suggested that cholangiocarcinoma cells in hepatic stellate dual-conditioned medium had the most marked HUVEC lumen formation ability (47). Furthermore, tumor cells stimulate fibroblasts to produce angiogenic factors with indirect tumor-stromal cell interaction patterns (48) and CAFs are the principal secretors of MMP-2, membrane type 1-MMP (MT1-MMP) and VEGF. PI3K is involved in VM formation by MMP-2 and MT1-MMP, whereas activated MMP-2 and MT1-MMP degrade Ln-5 $\gamma 2$ into the pre-migratory fragments $\gamma 2$ and $\gamma 2 \mathrm{x}$, which are enriched around tumor cells to promote tumor cell invasion and VM formation. As such, antibodies against MMP-2 and MT1-MMP, PI3K inhibitors and Ln-5 $\gamma 2$ target short interfering RNA are able to inhibit VM formation (7). In melanoma cells, VEGF and reactive oxygen species (ROS) regulate cell formation in the lumen-like structure, an effect that is reversed by antioxidants (49). Zinc 
finger E-box-binding homologous box (ZEB1) promotes VM formation in colon cancer via epithelial-mesenchymal transition (EMT) (50). Improving our understanding of the integrated mechanisms by which CAFs modulate angiogenesis and VM in human tumors is key to identifying potential novel therapeutic targets for human tumors.

\section{Molecular signaling pathways by which CAFs promote tumor neo-angiogenesis}

Cells and non-cellular components are required for tumor neo-angiogenesis, and diverse molecular signaling pathways are involved (Table I).

$V E G F / V E G F$ receptor (VEGFR). VEGF, which signals via its cognate VEGFR, is required for angiogenesis under normal conditions and in cancer (51). It has been identified that activated stromal cells secrete specific molecules that promote the expression of VEGF from tumor cells, and that certain factors secreted by CAFs interact with VEGF to increase tumor angiogenesis and invasiveness. Esophageal squamous cell carcinoma is a highly angiogenic tumor type; biochemical studies have identified that the VEGF signaling pathway derived from activated stromal fibroblasts induces capillary formation in this disease (52). A study involving lung squamous cancer cells revealed that podoplanin downregulated VEGF-C and decreased angiogenic and lymphangiogenic metastases (53). Expression of podoplanin, which promotes breast cancer angiogenesis and lymphangiogenesis (54), is often reported in CAFs, and podoplanin has been identified to stimulate angiogenesis and lymphangiogenesis in invasive ductal carcinoma of the breast via upregulation of VEGF-C rather than VEGF-A or VEGF-D in cancer cells $(55,56)$. Galectin-1, a member of the galectin family of $\beta$-galactoside-binding proteins, is involved in cancer cell invasion and tumor angiogenesis (57-59). Galectin-1 has been reported to be upregulated in CAFs of gastric cancer cells (60), and it has been demonstrated that endogenous CAF-derived galectin-1 is essential for accelerating angiogenesis by enhancing VEGF expression in gastric cancer and VEGFR2 phosphorylation in epithelial cells (ECs) (61). The interaction between angiomodulin (AGM) and VEGF also facilitates angiogenesis (62). AGM has been reported to be overexpressed by CAFs in breast, colon, lung and uterus carcinomas (63), and so is considered to be a marker of cancer vasculature permeability (64).

Oxidative stress is known to promote tumor angiogenesis. G-protein-coupled estrogen receptor (GPER), hypoxia-inducible factor- $1 \alpha$ (HIF-1 $\alpha)$ and ROS are involved in the activation of fibroblasts and upregulation of VEGF expression. GPER knockdown eliminates VEGF expression in activated CAFs under hypoxic conditions, and it has been identified that breast CAFs promote hypoxia-dependent tumor angiogenesis in a HIF-1 $\alpha /$ GPER-dependent manner by mediating the expression of VEGF $(65,66)$. A study of p53-deficient colorectal xenograft tumor cells revealed that functional loss of p53 significantly increased tube formation and enhanced neovascularization in a VEGF-dependent manner in vitro and in vivo by upregulating ROS to activate stromal fibroblasts (67). Similarly, Jo et al (68) reported that oxidative stress stimulates angiogenesis in hepatocellular carcinoma via the protein kinase B/VEGF pathway.
It has been identified that endothelial progenitor cells (EPCs) are often located near microvessels in nasopharyngeal carcinoma, and that VEGF-A is overexpressed in stromal and tumor cells, indicating that CAFs may enhance angiogenesis in a VEGF-A- and SDF-1-dependent manner by recruiting EPCs from the bone marrow into tumor stroma (69).

In conclusion, VEGF is an important factor that promotes tumor angiogenesis by interacting with the secretome of CAFs. This suggests that anti-VEGF therapy should target VEGF itself as well as VEGF-coupled molecules. Such therapies may have marked anti-angiogenic effects.

SDF-1 (CXC12)/CXC chemokine receptor type 4 (CXCR-4). SDF-1, or CXC12, is a homeostatic chemokine that signals via CXCR-4, a G-protein-coupled receptor that is primarily secreted by hematopoietic progenitor cells and EPCs within injured sites. The SDF-1/CXCR-4 signaling axis has been reported to serve a role in recruiting EPCs to tumor stroma (70). A co-implantation tumor xenograft model revealed that CAFs were essential for angiogenesis-associated tumor progression in invasive human breast carcinoma because of their ability to secrete SDF-1 and recruit EPCs to the tumor site via CXCR-4, which is expressed by carcinoma cells (35). The same functional role of SDF1 was reported in nasopharyngeal carcinoma (69).

It has been reported that the SDF-1/CXCR-4 axis derived from CAFs boosts tumor angiogenesis or VM formation; however, its intrinsic regulatory mechanisms have not been fully elucidated. It has been suggested that fibroblast-derived SDF-1 enhances the invasiveness of pancreatic cancer cells, whereas SDF-1 promotes angiogenic responses in synergy with CXC chemokine ligand (CXCL)8 (71). In mouse xenografts of hepatocellular carcinomas, CAFs could form capillary-like structures, namely VM, via paracrine transforming growth factor- $\beta$ (TGF- $\beta$ ) and SDF-1 (72). In human fetal lung fibroblast (MRC-5) and human lung cancer (95D) cell lines, the SDF-1/CXCR-4 axis participated in HUVEC and 95D cell migration, as well as HUVEC tube formation and angiogenesis, but not in HUVEC or 95D proliferation (73). An in vitro tube formation assay of tongue cancer tissues revealed that tumor necrosis factor $\alpha$ indirectly enhances cancer angiogenesis by increasing activated fibroblast-derived SDF-1 (74). Furthermore, cyclo-oxygenase-2 (COX-2) has been reported to increase tumor stromal formation and angiogenesis by regulating the pro-angiogenic microenvironment via SDF-1/CXCR-4 signaling (75). These results suggest a significant role for the stromal SDF-1/CXCR-4 axis in promoting tumor growth and enhancing angiogenesis, in part via EPC recruitment.

TGF- $\beta / T G F-\beta$ receptor (TGF- $\beta R$ ). TGF- $\beta$ is a pleiotropic growth factor that is expressed by cancer and stromal cells. TGF- $\beta$ /TGF- $\beta$ R signaling is required for advanced carcinogenesis via EMT induction, angiogenesis and modification of the stromal compartment $(76,77)$. It has been identified that TGF- $\beta$ and hypoxia work synergistically to regulate VEGF expression in mRNA biosynthesis (78). However, extracellular TGF- $\beta$ signaling pathways that trigger angiogenesis are not well-understood. It has been reported that TGF- $\beta$-primed myofibroblast secretion upregulates VEGF, which in turn 
Table I. CAF regulation of tumor neo-angiogenesis.

\begin{tabular}{|c|c|c|c|}
\hline $\begin{array}{l}\text { Pro-angiogenic } \\
\text { factor }\end{array}$ & Receptor & Underlying molecular mechanism with tumor angiogenesis & (Refs.) \\
\hline VEGF & VEGFR & $\begin{array}{l}\text { CAFs promoted tumor angiogenesis by mediating the } \\
\text { expression of VEGF i) through its secretome or } \\
\text { ii) in a HIF- } 1 \alpha / \text { GPER-dependent manner }\end{array}$ & $(54-56,60-67)$ \\
\hline SDF-1 & CXCR-4 & $\begin{array}{l}\text { SDF-1/CXCR-4 axis derived from CAFs enhances } \\
\text { angiogenesis partly through EPC recruitment }\end{array}$ & $(35,70-75)$ \\
\hline TGF- $\beta$ & TGF- $\beta$ R & $\begin{array}{l}\text { TGF- } \beta \text { signaling pathway from CAFs triggers angiogenesis } \\
\text { by i) upregulating VEGF expression or ii) interacting with } \\
\text { other molecules and promotes VM formation }\end{array}$ & $(52,72,82-86)$ \\
\hline HGF & c-MET & $\begin{array}{l}\text { Upregulation of HGF from CAF involves promotion of tumor } \\
\text { angiogenesis through interaction with VEGF or TGF- } \beta_{1}\end{array}$ & $(84,88-89,95-96)$ \\
\hline PDGF & PDGFR & $\begin{array}{l}\text { PDGF signaling from CAFs may not merely stimulate tumor } \\
\text { angiogenesis, but may mediate resistance to anti-angiogenic } \\
\text { therapy }\end{array}$ & $(99,103)$ \\
\hline FAP & No specific receptor & $\begin{array}{l}\text { FAP expressed by CAF promotes angiogenesis by affecting } \\
\text { the balance of pro-angiogenic and anti-angiogenic mediators }\end{array}$ & $(105-109)$ \\
\hline MMPs & No specific receptor & $\begin{array}{l}\text { MMP from CAFs provides suitable conditions for tumor } \\
\text { angiogenesis by regulating the degradation and remodeling } \\
\text { of the ECM }\end{array}$ & $(113,114)$ \\
\hline
\end{tabular}

CAF, cancer-associated fibroblast; VEGF, vascular endothelial growth factor; VEGFR, VEGF receptor; HIF-1 $\alpha$, hypoxia-inducible factor $1 \alpha$; GPER, G-protein-coupled estrogen receptor; SDF-1, stromal cell-derived factor 1; CXCR-4, CXC chemokine receptor type 4; EPC, endothelial progenitor cell; TGF- $\beta$, transforming growth factor- $\beta$; TGF- $\beta$ R, TGF- $\beta$ receptor; VM, vasculogenic mimicry; HGF, hepatocyte growth factor; PDGF, platelet-derived growth factor; PDGFR, PDGF receptor; FAP, fibroblast activation protein; MMP, matrix metalloproteinase; ECM, extracellular matrix.

stimulates vascular formation by ECs co-cultured in a three-dimensional assay (52). VM has been identified to be an important complement in the tumor microcirculation $(4,22,79)$ as it is a tubular structure that is formed by tumor cells to transport nutrients, and molecules including vascular endothelial cadherin (VE-cad), MMPs and laminin have been reported to be critical for VM formation $(7,80,81)$. TGF- $\beta_{1}$ derived from CAFs was identified to be a central molecular regulator of mesenchymal stem cells, as well as having a tumor-promoting function in prostate carcinoma progression (82). Furthermore, co-implantation of CAFs with tumor cells in mouse xenografts has been reported to promote the formation of capillary-like structures in hepatocellular carcinomas. A gene knockdown assay and gain- and loss-of-function assays revealed that CAFs secrete TGF- $\beta$ and SDF-1, which activate VE-cad, MMP2 and Ln-5 $\gamma 2$ expression via TGF- $\beta$ R1 and CXCR-4 in tumor cells to promote the formation of VM. MicroRNA-101 subsequently inhibits VM formation by suppressing the TGF- $\beta$ and SDF- 1 signaling pathways (72).

Immunohistochemical data have revealed increased angiogenesis in mice co-injected with TGF- $\beta_{1}$-pretreated Mc38-luc cells (colon adenocarcinoma cell lines from murine origin) and CAFs, whereas tumor angiogenesis was significantly decreased in mice treated with the TGF- $\beta_{1}$-inhibitory peptide P17 (83). Similar results were observed in esophageal squamous epithelial cells (84) and gastric tumor cells (85). Reverse transcription-polymerase chain reaction and western blot analyses demonstrated that the expression of angiogenic factor genes ( $\alpha$-SMA and VEGF) was significantly increased in ovarian cancer cells treated with CAF condition medium. $\alpha$-SMA and VEGF downregulation in the intervention group indicated that the effects of CAF angiogenesis are dependent on the TGF- $\beta$ signaling pathway (86). However, the quantification of cluster of differentiation (CD)31(+) vessels in breast cancer tissues via immunostaining indicated no significant differences in angiogenesis between TGF- $\beta^{-}$xenograft and control groups, indicating that TGF- $\beta$ - fibroblasts stimulate tumor growth independently of angiogenesis (87).

Further studies are required to explain the inconsistencies in experimental results. Owing to the pleiotropy of TGF- $\beta$, few studies have investigated the molecular mechanisms by which it promotes tumor angiogenesis.

Hepatocyte growth factor (HGF)/c-MET. Angiogenesis begins with local degradation of the basement membrane surrounding capillaries, following which ECs undergo migration and morphogenesis, leading to new capillary structures. It has been identified that the pro-angiogenic properties of ECs were promoted by HGF upregulation (88), and there is crosstalk between the HGF signaling pathway and VEGF-A in ECs (89).

Diverse stromal cells in the TME release HGF, whereas cancer cells express its receptor c-MET (90). Conditioned medium genetic knockdown and overexpression studies 
have revealed that the $\mathrm{HGF} / \mathrm{c}-\mathrm{MET}$ axis serves a role in promoting tumorigenesis and invasion in various types of human cancer (91-94). HGF acts as a significant angiogenic growth factor in the development of esophageal squamous cell carcinoma, and an in vitro study revealed that HGF stimulates VEGF expression to enhance angiogenesis and tumor cell invasion and migration $(95,96)$. Microvessel density analysis in esophageal squamous cell carcinoma tissues has revealed that CAF-secreted TGF- $\beta_{1}$ and HGF are associated with the proliferation of epithelial cells and angiogenesis (84). As such, increasing our understanding of HGF upregulation in tumor tissues and its interaction with VEGF or TGF- $\beta_{1}$ may be beneficial.

Platelet-derived growth factor (PDGF)/PDGFR. PDGF is a dimeric protein with several variants: PDGF-AA, PDGF-BB, PDGF-AB, PDGF-CC and PDGF-DD (97). Different tumors may have different PDGF/PDGFR expression patterns, and PDGF can be expressed by cancer cells or CAFs $(98,99)$. PDGFR signaling has been reported to be associated with the progression of carcinoma (100) and the efficacy of chemotherapy $(101,102)$. In a cervical squamous cell carcinoma transgenic mouse model, treatment with PDGFR kinase inhibitor suppressed FGF2 and FGF7 expression in tumor stromal fibroblasts, which decreased neo-angiogenesis and tumor growth (103). Increased PDGF-C expression in the stromal cells of chemoresistant tumors contributes to increased neo-angiogenesis during anti-VEGF treatment (99). Together, the results of these studies suggest that CAFs may mediate resistance to anti-angiogenic therapy as well as stimulating tumor angiogenesis.

FAP. FAP is a type II cell-surface-bound transmembrane glycoprotein that is expressed in activated stromal fibroblasts (104). An in vivo study of FAP-deficient mouse models indicated a pro-angiogenic effect of FAP (105). Furthermore, increased VEGF expression is associated with FAP upregulation in human pancreatic adenocarcinoma (106), suggesting that CAF-driven angiogenesis may be regulated by FAP. A recent study by Koczorowska et al (107) utilized FAP loss- and gain-of-function systems to investigate the effects of FAP on the biological function and secreted proteome of CAFs. The results revealed that increased FAP activity led to a decrease in the anti-angiogenic protein pigment epithelium-derived factor (PEDF) and an increase in pro-angiogenic proteins angiopoietin-1 and VEGF-C in the secretome of CAFs; this suggests that FAP serves a pro-angiogenic function by affecting the balance of pro- and anti-angiogenic mediators. A previous study revealed that FAP-activated protoxin selectively killed FAP-expressing cells and inhibited tumor growth in xenograft models (108), and a FAP-targeted DNA vaccine shifted immune polarization from tumor-promoting to suppression of recruitment of tumor-associated inflammatory cells. This decreased metastasis, angiogenesis and lymphangiogenesis in a murine breast cancer model (109). Together, these previous studies indicate that FAP is associated with the secretion of pro-angiogenic or anti-vascular proteins. It may therefore be beneficial to determine the mechanisms responsible for maintaining the balance of FAP regulatory proteins.
MMPs. Fibroblasts are an important source of ECM-degrading proteases, including MMPs, which are zinc-dependent endopeptidases; this suggests that fibroblasts serve a critical role in ECM homeostasis $(110,111)$. Recent reports have revealed that tumor (MMP-1, -2 and -14) and stromal (MMP-9, -13 and -14) MMP expression is associated with tumor progression and is associated with squamous cell carcinoma invasion (112). MMP-13 secreted by activated fibroblasts promotes angiogenesis by releasing ECM-bound VEGF and increasing the invasive capabilities of squamous cell carcinoma cells in a mouse xenograft (113). Zigrino et al (114) used MMP-13 $13^{+/+}$ and null mice to identify that stromal MMP-13 is required for melanoma invasion, angiogenesis and metastasis. In summary, MMP serves an important function in regulating the degradation and remodeling of ECM to provide suitable conditions for tumor angiogenesis.

Other factors. In order to positively participate in neo-angiogenesis, human breast CAFs deposit and secrete more adrenomedullin (AM) compared with normal fibroblasts. AM blockade is able to impair tumor vascular formation and induce apoptosis (115). Notch signaling is an evolutionarily conserved pathway that regulates cell biological characteristics, whose accommodative dysfunction has been implicated in various tumors. It was recently reported that oral squamous cell carcinoma promotes angiogenesis by inducing Notch3 expression in CAFs, whereas other cancer cells have been identified to induce Notch3 expression in CAFs and promote angiogenesis (116). Chloride intracellular channel protein 3 (CLIC3) is a human intracellular $\mathrm{Cl}^{-}$channel and scaffolding protein that is overexpressed in various tumor types (117-119). An in vivo study confirmed that CLIC3, an abundant component of the CAF secretome, increases the invasive abilities of breast cancer cells as well as improving functional vascularization, processes which require active transglutaminase-2 (120). A previous study revealed that cell division cycle 42 effector protein 3 (Cdc42EP3) is required in CAFs to allow for the expression of key angiogenic factors; Cdc42EP3 or SEPT2 depletion in a mammary tumor model significantly decreased the angiogenic potential of CAFs in vivo (121). COX-2 and endogenous prostaglandins (PGs) are important determinants of tumor growth and tumor-associated angiogenesis. COX-2 and $\mathrm{PGE}_{2} / \mathrm{EP} 3 / \mathrm{EP} 4$ signaling regulate the tumor stromal pro-angiogenic microenvironment and enhance stromal formation via CXCL12/CXCR-4 chemokine systems. Conversely, COX-2 inhibitor has been identified to suppress stromal formation and angiogenesis in a mouse model of Lewis lung carcinoma by inhibiting CXCL12/CXCR-4 in vivo (75). The oncogenic potential of chronic lymphoid leukemia (CLL)-derived exosomes has been investigated in vitro and in vivo. CLL-derived exosomes stimulate stromal cells to induce increased angiogenesis, thus supporting survival and outgrowth (122). FGF-1/-3/FGF receptor (FGFR) 4 signaling derived from CAFs promotes colon cancer cell proliferation and angiogenesis via activating mitogen-activated protein kinase/extracellular-signal-regulated kinase (ERK) kinase/ERK and modulating MMP-7 expression (123). Endoglin (eng) (124), a co-receptor for several members of the TGF- $\beta$ family, has also been reported to be associated with the process of tumor angiogenesis. In a 


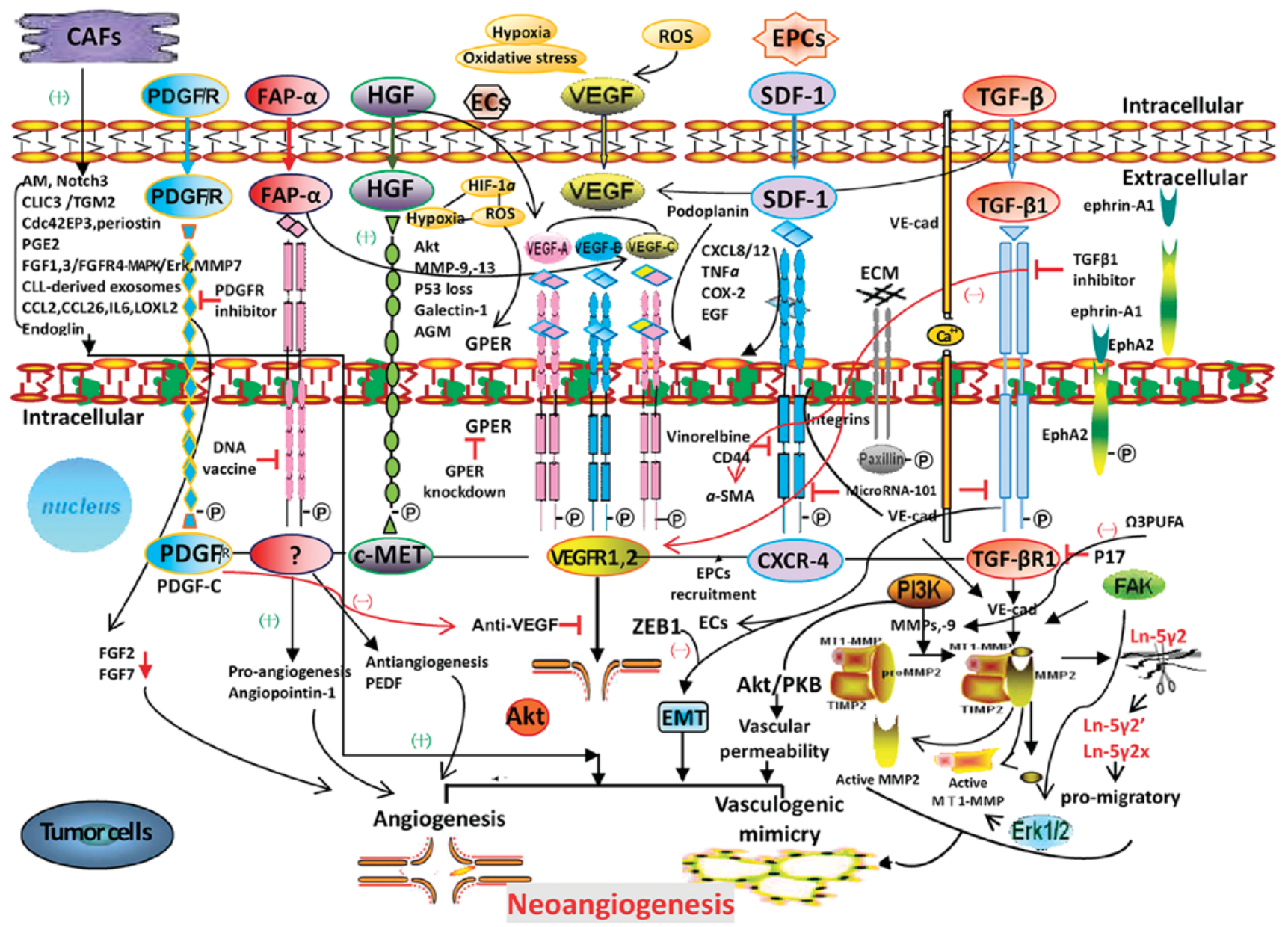

Figure 1. Molecular signaling pathways involved in CAFs regulation of tumor neo-angiogenesis and potential therapeutic targets for tumor angiogenesis and VM. T-shapes and (-) indicate inhibition; (+) indicates promoting. CAFs, cancer-associated fibroblasts; ECM, extracellular matrix; VEGF, vascular endothelial growth factor; VEGFR, VEGF receptor; PI3K, phosphoinositide 3-kinase; Ln-5 $\gamma 2$, laminin 5 $\gamma 2$; MMP, matrix metalloproteinase; MT1-MMP, membrane type 1-MMP; TIMP, tissue inhibitor of metalloproteinase; EphA2, ephrin type A receptor 2; $\alpha$-SMA, $\alpha$-smooth muscle actin; FAP, fibroblast activation protein; ROS, reactive oxygen species; ZEB1, zinc finger E-box-binding homologous box; GPER, G-protein-coupled estrogen receptor; HIF-1 $\alpha$, hypoxia-inducible factor-1 $\alpha$; AGM, angiomodulin; ECs, endothelial cells; EPCs, endothelial progenitor cells; SDF-1, stromal cell-derived factor-1; CXCR-4, CXC chemokine receptor type 4; TNF $\alpha$, tumor necrosis factor $\alpha$; COX-2, cyclo-oxygenase-2; EGF, epidermal growth factor; TGF- $\beta$, transforming growth factor- $\beta$; TGF- $\beta$ R, TGF- $\beta$ receptor; VE-cad, vascular endothelial cadherin; HGF, hepatocyte growth factor; PDGF, platelet-derived growth factor; PDGFR, PDGF receptor; PEDF, pigment epithelium-derived factor; AM, adrenomedullin; CLIC3, chloride intracellular channel protein 3; TGM2, transglutaminase-2; CLL, chronic lymphoid leukemia; FGF, fibroblast growth factor; FGFR, FGF receptor; MAPK, mitogen-activated protein kinase; IL6, interleukin 6; LOXL2, lysyl oxidase-like 2; $\Omega 3 \mathrm{PUFA}, \Omega-3$ polyunsaturated fatty acids; Akt/PKB, protein kinase B; CCL, CC chemokine ligand; CXCL, CXC chemokine ligand; Cdc42EP3, cell division cycle 42 effector protein 3; PGE2, prostaglandin $\mathrm{E}_{2}$; Erk, extracellular-signal-regulated kinase; FAK, focal adhesion kinase; CD44, cluster of differentiation $44 ; \mathrm{P}$, phospho.

transgenic adenocarcinoma mouse prostate (TRAMP) mouse model, increased vascularization occurred was observed in $\mathrm{eng}^{+/+}$mice compared with in eng ${ }^{+/-}$mice, suggesting that eng is required for multiple aspects of CAF function (125).

Tumor angiogenesis is a complicated and multi-factor process. In order to improve our understanding of it, the molecular delivery of each pathway and how multiple pathways are associated with each other require further investigation.

\section{Potential therapeutic targets}

As angiogenesis is a central process required for the growth of solid tumors, studies to clarify the molecular basis of CAFs-associated tumor angiogenesis have identified a number of potential antitumor agents. Such agents include SU5416 and Z24, which act as inhibitors of VEGFR and FGFR, respectively $(126,127)$. An in vitro study of 95D human lung cancer cells revealed that the addition of exogenous SDF-1 attenuates the anti-angiogenic effect of vinorelbine (VNR), suggesting that VNR may influence CAFs to cause SDF-1 and suppress tumor angiogenesis (73). Utilizing the unique enzymatic activity of FAP and its markedly restricted expression in reactive stroma, several tumor treatment strategies have been developed, including the use of small molecules and antibodies to inhibit enzyme activity, as well as immunosuppression to increase intratumoral drug concentrations. Potential mechanisms include decreasing blood vessel density and targeting CAF-associated molecular pathways (128). In vitro and in vivo experiments indicated that lenvatinib also exerts an anti-angiogenic effect by targeting VEGFR1-3 and FGFR1-4 (129). $\Omega-3$ polyunsaturated fatty acids may suppress MMP-9 expression and tumor angiogenesis (130). Initially, thalidomide was used as an effective antiemetic drug, but its anti-angiogenic effects were gradually identified and 
defined. Thalidomide can inhibit angiogenesis by targeting the expression of VEGF, FGF, FDGF, HIF and other molecules. However, clinical studies of thalidomide have not identified consistent antitumor effects (131).

A number of studies have identified that anti-pro-angiogenic agents alone are unable to elicit significant antitumor effects, suggesting that certain factors, such as activin A receptor like type 1 (ALK1), stabilize angiogenesis or convey resistance to anti-angiogenic effects. ALK1 is a transmembrane serine/threonine receptor kinase in the TGF- $\beta$ R family that is expressed on ECs (132). Intrinsic angiostatic drug resistance and extrinsic mechanisms may serve a role in the resistance of tumor cells to angiostatic therapy (133). Crawford et al (99) reported that CAFs from resistant tumors in a murine lymphoma model secreted more compensatory PDGF-C to promote sensitive tumor angiogenesis, even in the presence of anti-VEGF treatment (99). This suggests that tumors are able to activate stromal fibroblasts via different mechanisms. In a glioblastoma model, high PDGF-C expression in CAFs was associated with resistance to anti-VEGF treatment (134). On this basis, therapeutic regimens targeting VEGF and PDGF were attempted in an advanced renal cell carcinoma clinical trial; however, the trial had to be terminated owing to marked toxicity (135). In an animal experiment, treatment with CAFs-inhibitors plus oxaliplatin significantly decreased tumor growth and angiogenesis in colon cancer compared with the use of oxaliplatin or CAF inhibitors alone (136).

Additional factors have been identified to be associated with anti-angiogenesis. Kinugasa et al (137) observed that CAFs markedly express CD44 in hypoxic and avascular areas, and that CD44 was markedly increased following treatment with angiogenesis inhibitors in vitro. Similarly, periostin, an ECM protein that is principally produced by CAFs, was also hypothesized to be a crucial molecular mediator involved in tumor resistance to anti-angiogenic therapy (138).

These studies indicate that anti-angiogenesis strategies must target angiogenic factors as well as internal molecules that stabilize angiogenesis, while also considering clinical toxicity. CAFs regulate tumor neo-angiogenesis; the molecular signaling pathways by which CAFs may promote tumor neo-angiogenesis and potential therapeutic targets for tumor angiogenesis and VM are depicted in Fig. 1. It is hoped that future studies are able to identify successful therapies utilizing multiple targets and signaling pathways for tumor treatment.

\section{Conclusion}

The TME and neo-angiogenesis are essential for tumor progression, and so the underlying molecular signaling pathways of CAFs in human tumors are increasingly being investigated. As components of tumor stroma, CAFs may serve as potential therapeutic targets owing to their role in tumor progression. Growth factors and cytokines have also been investigated as potential drug targets for impairing interactions between CAFs and cancer cells. To date, a number of non-clinical studies utilizing anti-angiogenic strategies with multi-molecular combinations have elicited promising results. However, clinical investigations have not yet yielded significant results. Further studies should be performed to identify effective therapeutic targets and treatment options to block tumor metastasis and recurrence.

\section{Acknowledgements}

Not applicable.

\section{Funding}

The present review was supported by the National Natural Science Foundation of China (grant nos. 30672073 and 81372614).

\section{Availability of data and materials}

Not applicable.

\section{Authors' contributions}

FTW and WS wrote the paper. JTZ edited and formatted the paper. YZF revised the paper and prepared the figure. All authors have read and approved the final manuscript.

\section{Ethics approval and consent to participate}

Not applicable.

\section{Patient consent for publication}

Not applicable.

\section{Competing interests}

The authors declare that they have no competing interests.

\section{References}

1. Folkman J: Anti-angiogenesis: New concept for therapy of solid tumors. Ann Surg 175: 409-416, 1972.

2. Huang $G$ and Chen L: Tumor vasculature and microenvironment normalization: A possible mechanism of antiangiogenesis therapy. Cancer Biother Radiopharm 23: 661-667, 2008.

3. Maniotis AJ, Folberg R, Hess A, Seftor EA, Gardner LM, Pe'er J, Trent JM, Meltzer PS and Hendrix MJ: Vascular channel formation by human melanoma cells in vivo and in vitro: Vasculogenic mimicry. Am J Pathol 155: 739-752, 1999.

4. Folberg R, Hendrix M and Maniotis A: Vasculogenic mimicry and tumor angiogenesis. Am J Pathol 156: 361-381, 2000.

5. Senger D and Davis G: Angiogenesis. Cold Spring Harb Perspect Biol 3: a005090, 2011.

6. Rhee $\mathrm{J}$ and Hoff P: Angiogenesis inhibitors in the treatment of cancer. Expert Opin Pharmacother 6: 1701-1711, 2005.

7. Fan YZ and Sun W: Molecular regulation of vasculogenic mimicry in tumors and potential tumor-target therapy. World J Gastrointest Surg 2: 117-127, 2010.

8. Chen HX and Cleck JN: Adverse effects of anticancer agents that target the VEGF pathway. Nat Rev Clin Oncol 6: 465-477, 2009.

9. Higa GM and Abraham J: Biological mechanisms of bevacizumab-associated adverse events. Expert Rev Anticancer Ther 9: 999-1007, 2009.

10. Liotta LA and Kohn EC: The microenvironment of the tumour-host interface. Nature 411: 375-379, 2001.

11. Reisfeld RA: The tumor microenvironment: A target for combination therapy of breast cancer. Crit Rev Oncog 18: 115-133, 2013.

12. Micke P and Ostman A: Tumour-stroma interaction: Cancerassociated fibroblasts as novel targets in anti-cancer therapy? Lung Cancer 45 (Suppl 2): S163-S175, 2004.

13. Franco OE, Shaw AK, Strand DW and Hayward SW: Cancer associated fibroblasts in cancer pathogenesis. Semin Cell Dev Biol 21: 33-39, 2010 
14. O'Reilly MS: Antiangiogenesis and vascular endothelial growth factor/vascular endothelial growth factor receptor targeting as part of a combined-modality approach to the treatment of cancer. Int J Radiat Oncol Biol Phys 69: S64-S66, 2007.

15. Hajitou A, Sounni NE, Devy L, Grignet-Debrus C, Lewalle JM, Li H, Deroanne C, Lu H, Colige A, Nusgens BV, et al: Down-regulation of vascular endothelial growth factor by tissue inhibitor of metalloproteinase-2: Effect on in vivo mammary tumor growth and angiogenesis. Cancer Res 61: 3450-3457, 2001.

16. Sato M, Arap W and Pasqualini R: Molecular targets on blood vessels for cancer therapies in clinical trials. Oncology (Williston Park) 21: 1346-1355, 1367, 1370 passim, 2007.

17. Zhang JT, Fan YZ, Chen CQ, Zhao ZM and Sun W: Norcantharidin: A potential antiangiogenic agent for gallbladder cancers in vitro and in vivo. Int J Oncol 40: 1501-1514, 2012.

18. Ma $\mathbf{J}$ and Waxman DJ: Combination of antiangiogenesis with chemotherapy for more effective cancer treatment. Mol Cancer Ther 7: 3670-3684, 2008

19. Kamrava M, Bernstein MB, Camphausen $\mathrm{K}$ and Hodge J: Combining radiation, immunotherapy, and antiangiogenesis agents in the management of cancer: The Three Musketeers or just another quixotic combination? Mol Biosyst 5: 1262-1270, 2009.

20. Frenkel S, Barzel I, Levy J, Lin AY, Bartsch DJ, Majumdar D, Folberg R and Pe'er J: Demonstrating circulation in vasculogenic mimicry patterns of uveal melanoma by confocal indocyanine green angiography. Eye (Lond) 22: 948-952, 2008.

21. Xu Y, Li Q, Li XY, Yang QY, Xu WW and Liu GL: Short-term anti-vascular endothelial growth factor treatment elicits vasculogenic mimicry formation of tumors to accelerate metastasis. J Exp Clin Cancer Res 31: 16, 2012.

22. Sun W, Fan YZ, Zhang WZ and Ge CY: A pilot histomorphology and hemodynamic of vasculogenic mimicry in gallbladder carcinomas in vivo and in vitro. J Exp Clin Cancer Res 30: 46, 2011.

23. Lu XS, Sun W, Ge CY, Zhang WZ and Fan YZ: Contribution of the PI3K/MMPs/Ln-5 $\gamma 2$ and EphA2/FAK/Paxillin signaling pathways to tumor growth and vasculogenic mimicry of gallbladder carcinomas. Int J Oncol 42: 2103-2115, 2013.

24. Zhang JT, Sun W, Zhang WZ, Ge CY, Liu ZY, Zhao ZM, Lu XS and Fan YZ: Norcantharidin inhibits tumor growth and vasculogenic mimicry of human gallbladder carcinomas by suppression of the PI3-K/MMPs/Ln-5 22 signaling pathway. BMC Cancer 14: 193, 2014.

25. Wang H, Sun W, Zhang WZ, Ge CY, Zhang JT, Liu ZY and Fan YZ: Inhibition of tumor vasculogenic mimicry and prolongation of host survival in highly aggressive gallbladder cancers by norcantharidin via blocking the ephrin type a receptor 2/focal adhesion kinase/paxillin signaling pathway. PLoS One 9: e96982, 2014.

26. Zhu W, Sun W, Zhang JT, Liu ZY, Li XP and Fan YZ: Norcantharidin enhances TIMP-2 anti-vasculogenic mimicry activity for human gallbladder cancers through downregulating MMP-2 and MT1-MMP. Int J Oncol 46: 627-640, 2015.

27. Han H, Du L, Cao Z, Zhang B and Zhou Q: Triptonide potently suppresses pancreatic cancer cell-mediated vasculogenic mimicry by inhibiting expression of VE-cadherin and chemokine ligand 2 genes. Eur J Pharmacol 818: 593-603, 2018.

28. Chen J, Zhao M, Zhisheng Z, Lin C, Yayun Q, Xuanyi W, Feng J, Haibo W, Youyang S, Tadashi $\mathrm{H}$, et al: COE inhibits vasculogenic mimicry in hepatocellular carcinoma via suppressing Notch1 signaling. J Ethnopharmacol 208: 165-173, 2017.

29. Zhang F, Zhang CM, Li S, Wang KK, Guo BB, Fu Y, Liu LY, Zhang Y, Jiang HY and Wu CJ: Low dosage of arsenic trioxide inhibits vasculogenic mimicry in hepatoblastoma without cell apoptosis. Mol Med Rep 17: 1573-1582, 2018.

30. Li S, Zhang Q, Zhou L, Guan Y, Chen S, Zhang Y and Han X: Inhibitory effects of compound DMBT on hypoxia-induced vasculogenic mimicry in human breast cancer. Biomed Pharmacother 96: 982-992, 2017.

31. Angara K, Rashid MH, Shankar A, Ara R, Iskander A, Borin TF, Jain M, Achyut BR and Arbab AS: Vascular mimicry in glioblastoma following anti-angiogenic and anti-20-HETE therapies. Histol Histopathol 32: 917-928, 2017.

32. Xue W, Du XS, Wu H, Liu H, Xie T, Tong HP, Chen X, Guo Y and Zhang WG: Aberrant glioblastoma neovascularization patterns and their correlation with DCE-MRI-derived parameters following temozolomide and bevacizumab treatment. Sci Rep 7: 13894, 2017.
33. Zang M, Hu L, Zhang B, Zhu Z, Li J, Zhu Z, Yan M and Liu B: Luteolin suppresses angiogenesis and vasculogenic mimicry formation through inhibiting Notchl-VEGF signaling in gastric cancer. Biochem Biophys Res Commun 490: 913-919, 2017.

34. Liu W, Lv C, Zhang B, Zhou Q and Cao Z: MicroRNA-27b functions as a new inhibitor of ovarian cancer-mediated vasculogenic mimicry through suppression of VE-cadherin expression. RNA 23: 1019-1027, 2017.

35. Orimo A, Gupta P, Sgroi D, Arenzana-Seisdedos F, Delaunay T, Naeem R, Carey V, Richardson A and Weinberg R: Stromal fibroblasts present in invasive human breast carcinomas promote tumor growth and angiogenesis through elevated SDF-1/CXCL12 secretion. Cell 121: 335-348, 2005.

36. Sugimoto H, Mundel T, Kieran M and Kalluri R: Identification of fibroblast heterogeneity in the tumor microenvironment. Cancer Biol Ther 5: 1640-1646, 2006.

37. Johansson A, Ansell A, Jerhammar F, Lindh M, Grénman R, Munck-Wikland E, Östman A and Roberg K: Cancer-associated fibroblasts induce matrix metalloproteinase-mediated cetuximab resistance in head and neck squamous cell carcinoma cells. Mol Cancer Res 10: 1158-1168, 2012

38. Affolter A, Schmidtmann I, Mann WJ and Brieger J: Cancer-associated fibroblasts do not respond to combined irradiation and kinase inhibitor treatment. Oncol Rep 29: 785-790, 2013.

39. Al-Ansari MM, Hendrayani SF, Tulbah A, Al-Tweigeri T, Shehata AL and Aboussekhra A: p16INK4A represses breast stromal fibroblasts migration/invasion and theirVEGF-A-dependent promotion of angiogenesis through Akt inhibition. Neoplasia 14: 1269-1277, 2012

40. Gao Q, Wang XY, Qiu SJ, Zhou J, Shi YH, Zhang BH and Fan J: Tumor stroma reaction-related gene signature predicts clinical outcome in human hepatocellular carcinoma. Cancer Sci 102: $1522-1531,2011$

41. Herrera M, Herrera A, Domínguez G, Silva J, García V, García J, Gómez I, Soldevilla B, Muñoz C, Provencio M, et al: Cancer-associated fibroblast and M2 macrophage markers together predict outcome in colorectal cancer patients. Cancer Sci 104: 437-444, 2013.

42. Madar S, Goldstein I and Rotter V: 'Cancer associated fibroblasts' -more than meets the eye. Trends Mol Med 19: 447-453, 2013.

43. Gonda TA, Varro A, Wang TC and Tycko B: Molecular biology of cancer-associated fibroblasts: Can these cells be targeted in anti-cancer therapy? Semin Cell Dev Biol 21: 2-10, 2010.

44. Mertens J, Fingas CD, Christensen JD, Smoot RL, Bronk SF, Werneburg NW, Gustafson MP, Dietz AB, Roberts LR, Sirica AE and Gores GJ: Therapeutic effects of deleting cancer-associated fibroblasts in cholangiocarcinoma. Cancer Res 73: 897-907, 2013.

45. Olive KP, Jacobetz MA, Davidson CJ, Gopinathan A, McIntyre D, Honess D, Madhu B, Goldgraben MA, Caldwell ME, Allard D, et al: Inhibition of Hedgehog signaling enhances delivery of chemotherapy in a mouse model of pancreatic cancer. Science 324: 1457-1461, 2009.

46. Fukumura D, Xavier R, Sugiura T, Chen Y, Park EC, Lu N, Selig M, Nielsen G, Taksir T, Jain RK and Seed B: Tumor induction of VEGF promoter activity in stromal cells. Cell 94: 715-725, 1998.

47. Okabe H, Beppu T, Hayashi H, Ishiko T, Masuda T, Otao R, Horlad H, Jono H, Ueda M, Shinriki S, et al: Hepatic stellate cells accelerate the malignant behavior of cholangiocarcinoma cells. Ann Surg Oncol 18: 1175-1184, 2011.

48. Guo X, Oshima H, Kitmura T, Taketo M and Oshima M: Stromal fibroblasts activated by tumor cells promote angiogenesis in mouse gastric cancer. J Biol Chem 283: 19864-19871, 2008.

49. Vartanian AA, Burova OS, Stepanova EV, Baryshnikov AY and Lichinitser MR: Melanoma vasculogenic mimicry is strongly related to reactive oxygen species level. Melanoma Res 17: 370-379, 2007.

50. Liu Z, Sun B, Qi L, Li H, Gao J and Leng X: Zinc finger E-box binding homeobox 1 promotes vasculogenic mimicry in colorectal cancer through induction of epithelial-to-mesenchymal transition. Cancer Sci 103: 813-820, 2012.

51. Carmeliet P and Jain R: Molecular mechanisms and clinical applications of angiogenesis. Nature 473: 298-307, 2011.

52. Noma K, Smalley KS, Lioni M, Naomoto Y, Tanaka N, El-Deiry W, King AJ, Nakagawa H and Herlyn M: The essential role of fibroblasts in esophageal squamous cell carcinoma-induced angiogenesis. Gastroenterology 134: 1981-1993, 2008. 
53. Suzuki H, Onimaru M, Yonemitsu Y, Maehara Y, Nakamura S and Sueishi K: Podoplanin in cancer cells is experimentally able to attenuate prolymphangiogenic and lymphogenous metastatic potentials of lung squamoid cancer cells. Mol Cancer 9: 287, 2010.

54. Schoppmann SF, Jesch B, Riegler MF, Maroske F, Schwameis K, Jomrich G and Birner P: Podoplanin expressing cancer associated fibroblasts are associated with unfavourable prognosis in adenocarcinoma of the esophagus. Clin Exp Metastasis 30: 441-446, 2013

55. Pula B, Jethon A, Piotrowska A, Gomulkiewicz A, Owczarek T, Calik J, Wojnar A, Witkiewicz W, Rys J, Ugorski M, etal: Podoplanin expression by cancer-associated fibroblasts predicts poor outcome in invasive ductal breast carcinoma. Histopathology 59: 1249-1260, 2011.

56. Pula B, Wojnar A, Witkiewicz W, Dziegiel $\mathrm{P}$ and Podhorska-Okolow M: Podoplanin expression in cancer-associated fibroblasts correlates with VEGF-C expression in cancer cells of invasive ductal breast carcinoma. Neoplasma 60: 516-524, 2013.

57. Tang D, Yuan Z, Xue X, Lu Z, Zhang Y, Wang H, Chen M, An Y, Wei J, Zhu Y, et al: High expression of Galectin-1 in pancreatic stellate cells plays a role in the development and maintenance of an immunosuppressive microenvironment in pancreatic cancer. Int J Cancer 130: 2337-2348, 2012.

58. Wu MH, Hong TM, Cheng HW, Pan SH, Liang YR, Hong HC, Chiang WF, Wong TY, Shieh DB, Shiau AL, et al: Galectin-1-mediated tumor invasion and metastasis, up-regulated matrix metalloproteinase expression, and reorganized actin cytoskeletons. Mol Cancer Res 7: 311-318, 2009.

59. Thijssen VL, Postel R, Brandwijk RJ, Dings RP, Nesmelova I, Satijn S, Verhofstad N, Nakabeppu Y, Baum L, Bakkers J, et al: Galectin-1 is essential in tumor angiogenesis and is a target for antiangiogenesis therapy. Proc Natl Acad Sci USA 103: 15975-15980, 2006

60. Bektas S, Bahadir B, Ucan BH and Ozdamar SO: CD24 and galectin-1 expressions in gastric adenocarcinoma and clinicopathologic significance. Pathol Oncol Res 16: 569-577, 2010.

61. Tang D, Gao J, Wang S, Ye N, Chong Y, Huang Y, Wang J, Li B, Yin W and Wang D: Cancer-associated fibroblasts promote angiogenesis in gastric cancer through galectin-1 expression. Tumour Biol 37: 1889-1899, 2016.

62. Hooper AT, Shmelkov SV, Gupta S, Milde T, Bambino K, Gillen K, Goetz M, Chavala S, Baljevic M, Murphy A, et al: Angiomodulin is a specific marker of vasculature and regulates vascular endothelial growth factor-A-dependent neoangiogenesis. Circ Res 105: 201-208, 2009.

63. Komiya E, Furuya M, Watanabe N, Miyagi Y, Higashi S and Miyazaki K: Elevated expression of angiomodulin (AGM/IGFBP-rP1) in tumor stroma and its roles in fibroblas activation. Cancer Sci 103: 691-699, 2012.

64. Komiya E, Sato H, Watanabe N, Ise M, Higashi S, Miyagi Y and Miyazaki K: Angiomodulin, a marker of cancer vasculature, is upregulated by vascular endothelial growth factor and increases vascular permeability as a ligand of integrin $\alpha v \beta 3$. Cancer Med 3: 537-549, 2014

65. Ren J, Guo H, Wu H, Tian T, Dong D, Zhang Y, Sui Y, Zhang Y, Zhao D, Wang S, et al: GPER in CAFs regulates hypoxia-driven breast cancer invasion in a CTGF-dependent manner. Oncol Rep 33: 1929-1937, 2015.

66. De Francesco E, Lappano R, Santolla M, Marsico S, Caruso A and Maggiolini M: HIF-1 $\alpha /$ GPER signaling mediates the expression of VEGF induced by hypoxia in breast cancer associated fibroblasts (CAFs). Breast Cancer Res 15: R64, 2013.

67. Hayashi Y, Tsujii M, Kodama T, Akasaka T, Kondo J, Hikita H, Inoue T, Tsujii Y, Maekawa A, Yoshii S, et al: p53 functional deficiency in human colon cancer cells promotes fibroblast-mediated angiogenesis and tumor growth. Carcinogenesis 37: 972-984, 2016.

68. Jo M, Nishikawa T, Nakajima T, Okada Y, Yamaguchi K, Mitsuyoshi H, Yasui K, Minami M, Iwai M, Kagawa K, et al: Oxidative stress is closely associated with tumor angiogenesis of hepatocellular carcinoma. J Gastroenterol 46: 809-821, 2011.

69. Wang S, Ma N, Kawanishi S, Hiraku Y, Oikawa S, Xie Y,Zhang Z, Huang $G$ and Murata M: Relationships of alpha-SMA-positive fibroblasts and SDF-1-positive tumor cells with neoangiogenesis in nasopharyngeal carcinoma. Biomed Res Int 2014: 507353, 2014.

70. Orimo A and Weinberg R: Stromal fibroblasts in cancer: A novel tumor-promoting cell type. Cell Cycle 5: 1597-1601, 2006.
71. Matsuo Y, Ochi N, Sawai H, Yasuda A, Takahashi H, Funahashi H, Takeyama H, Tong $\mathrm{Z}$ and Guha S: CXCL8/IL-8 and CXCL12/SDF-1 alpha co-operatively promote invasiveness and angiogenesis in pancreatic cancer. Int J Cancer 124: 853-861, 2009.

72. Yang J, Lu Y, Lin YY, Zheng ZY, Fang JH, He S and Zhuang SM: Vascular mimicry formation is promoted by paracrine TGF- $\beta$ and SDF1 of cancer-associated fibroblasts and inhibited by miR-101 in hepatocellular carcinoma. Cancer Lett 383: 18-27, 2016.

73. Fang D, Sun L, Lin S, Zhou L, Su N, Yuan S and Yu B: Vinorelbine inhibits angiogenesis and 95D migration via reducing hypoxic fibroblast stromal cell-derived factor 1 secretion. Exp Biol Med (Maywood) 237: 1045-1055, 2012.

74. Zhou B, Zhuang XM, Wang YY, Lin ZY, Zhang DM, Fan S, Li JS and Chen WL: Tumor necrosis factor $\alpha$ induces myofibroblast differentiation in human tongue cancer and promotes invasiveness and angiogenesis via secretion of stromal cell-derived factor-1. Oral Oncol 51: 1095-1102, 2015.

75. Katoh H, Hosono K, Ito Y, Suzuki T, Ogawa Y, Kubo H, Kamata H, Mishima T, Tamaki H, Sakagami H, et al: COX-2 and prostaglandin EP3/EP4 signaling regulate the tumor stromal proangiogenic microenvironment via CXCL12-CXCR4 chemokine systems. Am J Pathol 176: 1469-1483, 2010.

76. Massagué J: TGF $\beta$ signalling in context. Nat Rev Mol Cell Biol 13: 616-630, 2012.

77. Meulmeester E and Ten Dijke P: The dynamic roles of TGF- $\beta$ in cancer. J Pathol 223: 205-218, 2011.

78. Sánchez-Elsner T, Botella L, Velasco B, Corbí A, Attisano L and Bernabéu C: Synergistic cooperation between hypoxia and transforming growth factor-beta pathways on human vascular endothelial growth factor gene expression. J Biol Chem 276: 38527-38535, 2001.

79. Schnegg C, Yang MH, Ghosh SK and Hsu MY: Induction of vasculogenic mimicry overrides VEGF-A silencing and enriches stem-like cancer cells in melanoma. Cancer Res 75: 1682-1690, 2015.

80. Seftor RE, Hess AR, Seftor EA, Kirschmann DA, Hardy KM, Margaryan NV and Hendrix MJ: Tumor cell vasculogenic mimicry: From controversy to therapeutic promise. Am J Pathol 181: 1115-1125, 2012.

81. Kirschmann DA, Seftor EA, Hardy KM, Seftor RE and Hendrix MJ: Molecular pathways: Vasculogenic mimicry in tumor cells: Diagnostic and therapeutic implications. Clin Cancer Res 18: 2726-2732, 2012.

82. Barcellos-de-Souza P, Comito G, Pons-Segura C, Taddei ML, Gori V, Becherucci V, Bambi F, Margheri F, Laurenzana A, Del Rosso M, et al: Mesenchymal stem cells are recruited and activated into carcinoma-associated fibroblasts by prostate cancer microenvironment-derived TGF- $\beta 1$. Stem Cells 34: 2536-2547, 2016

83. Gonzalez-Zubeldia I, Dotor J, Redrado M, Bleau A, Manrique I, de Aberasturi A, Villalba M and Calvo A: Co-migration of colon cancer cells and CAFs induced by TGF $\beta_{1}$ enhances liver metastasis. Cell Tissue Res 359: 829-839, 2015

84. Xu Z, Wang S, Wu M, Zeng W, Wang X and Dong Z: TGFß1 and HGF protein secretion by esophageal squamous epithelial cells and stromal fibroblasts in oesophageal carcinogenesis. Oncol Lett 6: 401-406, 2013

85. Saito H, Tsujitani S, Oka S, Kondo A, Ikeguchi M, Maeta M and Kaibara N: The expression of transforming growth factor-beta1 is significantly correlated with the expression of vascular endothelial growth factor and poor prognosis of patients with advanced gastric carcinoma. Cancer 86: 1455-1462, 1999.

86. Xu LN, Xu BN, Cai J, Yang JB and Lin N: Tumor-associated fibroblast-conditioned medium promotes tumor cell proliferation and angiogenesis. Genet Mol Res 12: 5863-5871, 2013

87. Guido C, Whitaker-Menezes D, Capparelli C, Balliet R, Lin Z, Pestell R, Howell A, Aquila S, Andò S, Martinez-Outschoorn U, et al: Metabolic reprogramming of cancer-associated fibroblasts by TGF- $\beta$ drives tumor growth: Connecting TGF- $\beta$ signaling with 'Warburg-like' cancer metabolism and L-lactate production. Cell Cycle 11: 3019-3035, 2012.

88. Ding S, Merkulova-Rainon T, Han ZC and Tobelem G: HGF receptor up-regulation contributes to the angiogenic phenotype of human endothelial cells and promotes angiogenesis in vitro. Blood 101: 4816-4822, 2003

89. Sulpice E, Ding S, Muscatelli-Groux B, Bergé M, Han Z, Plouet J, Tobelem $\mathrm{G}$ and Merkulova-Rainon T: Cross-talk between the VEGF-A and HGF signalling pathways in endothelial cells. Biol Cell 101: 525-539, 2009 
90. Spina A, De Pasquale V, Cerulo G, Cocchiaro P, Della Morte R, Avallone L and Pavone L: HGF/c-MET axis in tumor microenvironment and metastasis formation. Biomedicines 3: 71-88, 2015.

91. Grugan KD, Miller CG, Yao Y, Michaylira CZ, Ohashi S, Klein-Szanto AJ, Diehl A, Herlyn M, Han M, Nakagawa H and Rustgi AK: Fibroblast-secreted hepatocyte growth factor plays a functional role in esophageal squamous cell carcinoma invasion. Proc Natl Acad Sci USA 107: 11026-11031, 2010.

92. Wu X, Chen X, Zhou Q, Li P, Yu B, Li J, Qu Y, Yan J, Yu Y, Yan M, et al: Hepatocyte growth factor activates tumor stromal fibroblasts to promote tumorigenesis in gastric cancer. Cancer Lett 335: 128-135, 2013.

93. Jia C, Wang T, Liu W, Fu B, Hua X, Wang G, Li T, Li X, Wu X, Tai Y, et al: Cancer-associated fibroblasts from hepatocellular carcinoma promote malignant cell proliferation by HGF secretion. PLoS One 8: e63243, 2013.

94. Tyan SW, Kuo WH, Huang CK, Pan CC, Shew JY, Chang KJ, Lee EY and Lee WH: Breast cancer cells induce cancer-associated fibroblasts to secrete hepatocyte growth factor to enhance breast tumorigenesis. PLoS One 6: e15313, 2011.

95. Ren Y, Cao B, Law S, Xie Y, Lee PY, Cheung L, Chen Y, Huang X, Chan HM, Zhao P, et al: Hepatocyte growth factor promotes cancer cell migration and angiogenic factors expression: A prognostic marker of human esophageal squamous cell carcinomas. Clin Cancer Res 11: 6190-6197, 2005.

96. Oshima Y, Yajima S, Yamazaki K, Matsushita K, Tagawa M and Shimada H: Angiogenesis-related factors are molecular targets for diagnosis and treatment of patients with esophageal carcinoma. Ann Thorac Cardiovasc Surg 16: 389-393, 2010

97. Bergsten E, Uutela M, Li X, Pietras K, Ostman A, Heldin C, Alitalo $\mathrm{K}$ and Eriksson U: PDGF-D is a specific, protease-activated ligand for the PDGF beta-receptor. Nat Cell Biol 3 : $512-516,2001$

98. Kitadai Y, Sasaki T, Kuwai T, Nakamura T, Bucana C and Fidler I: Targeting the expression of platelet-derived growth factor receptor by reactive stroma inhibits growth and metastasis of human colon carcinoma. Am J Pathol 169: 2054-2065, 2006.

99. Crawford Y, Kasman I, Yu L, Zhong C, Wu X, Modrusan Z, Kaminker $\mathrm{J}$ and Ferrara N: PDGF-C mediates the angiogenic and tumorigenic properties of fibroblasts associated with tumors refractory to anti-VEGF treatment. Cancer Cell 15: 21-34, 2009.

100. Ostman A: PDGF receptors-mediators of autocrine tumor growth and regulators of tumor vasculature and stroma. Cytokine Growth Factor Rev 15: 275-286, 2004.

101. Pietras K, Rubin K, Sjöblom T, Buchdunger E, Sjöquist M, Heldin $\mathrm{C}$ and Ostman A: Inhibition of PDGF receptor signaling in tumor stroma enhances antitumor effect of chemotherapy. Cancer Res 62: 5476-5484, 2002

102. Pietras K, Gustafson AM, Sjoblom T, Buchdunger E, McSheehy P, Sjoquist M, Wartmann M, Reed R, Heldin CH, Rubin $\mathrm{K}$, et al: PDGF receptor inhibition in tumor stroma, with STI571 or PDGF B-chain aptamers, enhances the effects of chemotherapy in experimental solid tumors by increasing tumor drug uptake. Eur J Cancer 38: S91-S91, 2002.

103. Pietras K, Pahler J, Bergers G and Hanahan D: Functions of paracrine PDGF signaling in the proangiogenic tumor stroma revealed by pharmacological targeting. PLoS Med 5: e19, 2008

104.Zi F, He J, He D, Li Y, Yang L and Cai Z: Fibroblast activation protein $\alpha$ in tumor microenvironment: Recent progression and implications (review). Mol Med Rep 11: 3203-3211, 2015.

105. Santos AM, Jung J, Aziz N, Kissil JL and Puré E: Targeting fibroblast activation protein inhibits tumor stromagenesis and growth in mice. J Clin Invest 119: 3613-3625, 2009

106. Patsouras D, Papaxoinis K, Kostakis A, Safioleas MC, Lazaris AC and Nicolopoulou-Stamati P: Fibroblast activation protein and its prognostic significance in correlation with vascular endothelial growth factor in pancreatic adenocarcinoma. Mol Med Rep 11: 4585-4590, 2015.

107. Koczorowska MM, Tholen S, Bucher F, Lutz L, Kizhakkedathu JN, De Wever O, Wellner U, Biniossek ML, Stahl A, Lassmann S and Schilling O: Fibroblast activation protein- $\alpha$, a stromal cell surface protease, shapes key features of cancer associated fibroblasts through proteome and degradome alterations. Mol Oncol 10: 40-58, 2016.

108. LeBeau AM, Brennen WN, Aggarwal S and Denmeade SR: Targeting the cancer stroma with a fibroblast activation protein-activated promelittin protoxin. Mol Cancer Ther 8: 1378-1386, 2009
109. Liao D, Luo Y, Markowitz D, Xiang R and Reisfeld RA: Cancer associated fibroblasts promote tumor growth and metastasis by modulating the tumor immune microenvironment in a 4T1 murine breast cancer model. PLoS One 4: e7965, 2009.

110. Chang HY, Chi JT, Dudoit S, Bondre C, van de Rijn M, Botstein D and Brown PO: Diversity, topographic differentiation, and positional memory in human fibroblasts. Proc Nat Acad Sci USA 99: 12877-12882, 2002

111. Simian M, Hirai Y, Navre M, Werb Z, Lochter A and Bissell MJ: The interplay of matrix metalloproteinases, morphogens and growth factors is necessary for branching of mammary epithelial cells. Development 128: 3117-3131, 2001

112. Vosseler S, Lederle W, Airola K, Obermueller E, Fusenig NE and Mueller MM: Distinct progression-associated expression of tumor and stromal MMPs in HaCaT skin SCCs correlates with onset of invasion. Int J Cancer 125: 2296-2306, 2009.

113. Lederle W, Hartenstein B, Meides A, Kunzelmann H, Werb Z, Angel P and Mueller M: MMP13 as a stromal mediator in controlling persistent angiogenesis in skin carcinoma. Carcinogenesis 31: $1175-1184,2010$

114. Zigrino P, Kuhn I, Bäuerle T, Zamek J, Fox JW, Neumann S, Licht A, Schorpp-Kistner M, Angel P and Mauch C: Stromal expression of MMP-13 is required for melanoma invasion and metastasis. J Invest Dermatol 129: 2686-2693, 2009.

115. Benyahia Z, Dussault N, Cayol M, Sigaud R, Berenguer-Daizé C Delfino C, Tounsi A, Garcia S, Martin P, Mabrouk K and Ouafik L: Stromal fibroblasts present in breast carcinomas promote tumor growth and angiogenesis through adrenomedullin secretion. Oncotarget 8: 15744-15762, 2017.

116. Kayamori K, Katsube K, Sakamoto K, Ohyama Y, Hirai H, Yukimori A, Ohata Y, Akashi T, Saitoh M, Harada K, et al: NOTCH3 is induced in cancer-associated fibroblasts and promotes angiogenesis in oral squamous cell carcinoma. PLoS One 11: e0154112, 2016.

117. Tasiopoulou V, Magouliotis D, Solenov EI, Vavougios G, Molyvdas PA, Gourgoulianis KI, Hatzoglou C and Zarogiannis SG: Transcriptional over-expression of chloride intracellular channels 3 and 4 in malignant pleural mesothelioma. Comput Biol Chem 59 Pt A: 111-116, 2015.

118. Macpherson IR, Rainero E, Mitchell LE, van den Berghe PV, Speirs C, Dozynkiewicz MA, Chaudhary S, Kalna G, Edwards J, Timpson P and Norman JC: CLIC3 controls recycling of late endosomal MT1-MMP and dictates invasion and metastasis in breast cancer. J Cell Sci 127: 3893-3901, 2014.

119. Dozynkiewicz MA, Jamieson NB, Macpherson I, Grindlay J, van den Berghe $\mathrm{P}$, von Thun A, Morton JP, Gourley C, Timpson P, Nixon C, et al: Rab25 and CLIC3 collaborate to promote integrin recycling from late endosomes/lysosomes and drive cancer progression. Dev Cell 22: 131-145, 2012.

120. Hernandez-Fernaud JR, Ruengeler E, Casazza A, Neilson LJ, Pulleine E, Santi A, Ismail S, Lilla S, Dhayade S, MacPherson IR, et al: Secreted CLIC3 drives cancer progression through its glutathione-dependent oxidoreductase activity. Nat Commun 8: 14206, 2017.

121. Calvo F, Ranftl R, Hooper S, Farrugia AJ, Moeendarbary E, Bruckbauer A, Batista F, Charras G and Sahai E: Cdc42EP3/BORG2 and septin network enables mechano-transduction and the emergence of cancer-associated fibroblasts. Cell Rep 13: 2699-2714, 2015.

122. Paggetti J, Haderk F, Seiffert M, Janji B, Distler U, Ammerlaan W, Kim YJ, Adam J, Lichter P, Solary E, et al: Exosomes released by chronic lymphocytic leukemia cells induce the transition of stromal cells into cancer-associated fibroblasts. Blood 126 1106-1117, 2015

123. Bai YP, Shang K, Chen H, Ding F, Wang Z, Liang C, Xu Y, Sun MH and Li YY: FGF-1/-3/FGFR4 signaling in cancer-associated fibroblasts promotes tumor progression in colon cancer through Erk and MMP-7. Cancer Sci 106: 1278-1287, 2015.

124. Núñez-Gómez E, Pericacho M, Ollauri-Ibáñez C, Bernabéu C and López-Novoa J: The role of endoglin in post-ischemic revascularization. Angiogenesis 20: 1-24, 2017.

125. Romero D, O'Neill C, Terzic A, Contois L, Young K, Conley BA, Bergan RC, Brooks PC and Vary CP: Endoglin regulates cancer-stromal cell interactions in prostate tumors. Cancer Res 71: 3482-3493, 2011.

126. Mendel DB, Laird AD, Smolich BD, Blake RA, Liang C, Hannah AL, Shaheen RM, Ellis LM, Weitman S, Shawver LK and Cherrington JM: Development of SU5416, a selective small molecule inhibitor of VEGF receptor tyrosine kinase activity, as an anti-angiogenesis agent. Anticancer Drug Des 15: 29-41, 2000. 
127. Wang LL, Li JJ, Zheng ZB, Liu HY, Du GJ and Li S: Antitumor activities of a novel indolin-2-ketone compound, Z24: More potent inhibition on bFGF-induced angiogenesis and bcl-2 over-expressing cancer cells. Eur J Pharmacol 502: 1-10, 2004.

128. Brennen WN, Isaacs JT and Denmeade SR: Rationale behind targeting fibroblast activation protein-expressing carcinoma-associated fibroblasts as a novel chemotherapeutic strategy. Mol Cancer Ther 11: 257-266, 2012.

129. Yamamoto Y, Matsui J, Matsushima T, Obaishi H, Miyazaki K, Nakamura K, Tohyama O, Semba T, Yamaguchi A, Hoshi SS, et al: Lenvatinib, an angiogenesis inhibitor targeting VEGFR/FGFR, shows broad antitumor activity in human tumor xenograft models associated with microvessel density and pericyte coverage. Vasc Cell 6: 18, 2014.

130. Taguchi A, Kawana K, Tomio K, Yamashita A, Isobe Y Nagasaka K, Koga K, Inoue T, Nishida H, Kojima S, et al: Matrix metalloproteinase (MMP)-9 in cancer-associated fibroblasts (CAFs) is suppressed by omega-3 polyunsaturated fatty acids in vitro and in vivo. PLoS One 9: e89605, 2014.

131. Wang X, Shen Y, Li S, Lv M, Zhang X, Yang J, Wang F and Yang J: Importance of the interaction between immune cells and tumor vasculature mediated by thalidomide in cancer treatment (Review). Int J Mol Med 38: 1021-1029, 2016.

132. Hu-Lowe DD, Chen E, Zhang L, Watson KD, Mancuso P, Lappin $\mathrm{P}$, Wickman $\mathrm{G}$, Chen JH, Wang J, Jiang X, et al: Targeting activin receptor-like kinase 1 inhibits angiogenesis and tumorigenesis through a mechanism of action complementary to anti-VEGF therapies. Cancer Res 71: 1362-1373, 2011

133. Huijbers EJ, van Beijnum JR, Thijssen VL, Sabrkhany S, Nowak-Sliwinska P and Griffioen A: Role of the tumor stroma in resistance to anti-angiogenic therapy. Drug Resist Updat 25: $26-37,2016$
134. di Tomaso E, London N, Fuja D, Logie J, Tyrrell JA, Kamoun W, Munn LL and Jain RK: PDGF-C induces maturation of blood vessels in a model of glioblastoma and attenuates the response to anti-VEGF treatment. PLoS One 4: e5123, 2009.

135. Hainsworth JD, Spigel DR, Sosman JA, Burris HA III, Farley C, Cucullu H, Yost K, Hart LL, Sylvester L, Waterhouse DM and Greco FA: Treatment of advanced renal cell carcinoma with the combination bevacizumab/erlotinib/imatinib: A phase I/II trial. Clin Genitourin Cancer 5: 427-432, 2007.

136. Li M, Li M, Yin T, Shi H, Wen Y, Zhang B, Chen M, Xu G, Ren K and Wei Y: Targeting of cancer-associated fibroblasts enhances the efficacy of cancer chemotherapy by regulating the tumor microenvironment. Mol Med Rep 13: 2476-2484, 2016.

137. Kinugasa Y, Matsui T and Takakura N: CD44 expressed on cancer-associated fibroblasts is a functional molecule supporting the stemness and drug resistance of malignant cancer cells in the tumor microenvironment. Stem Cells 32: 145-156, 2014.

138. Wang W, Ma JL, Jia WD and Xu GL: Periostin: A putative mediator involved in tumour resistance to anti-angiogenic therapy? Cell Biol Int 35: 1085-1088, 2011.

cc) () $\odot$ This work is licensed under a Creative Commons C. Attribution-NonCommercial-NoDerivatives 4.0 International (CC BY-NC-ND 4.0) License. 